\title{
Bencana Alam Dan Kerja Bakti Masa Jawa Kuna Serta Catatan Lain Tentang Prasasti Nganjatan
}

\section{Rita Margaretha Setianingsih}

Keywords: inscription, tradition, community service, java, hindu-buddha

\section{How to Cite:}

Setianingsih, R. M. (1996). Bencana Alam Dan Kerja Bakti Masa Jawa Kuna Serta Catatan Lain Tentang Prasasti Nganjatan. Berkala Arkeologi, 16(2), 42-49. https://doi.org/10.30883/jba.v16i2.752

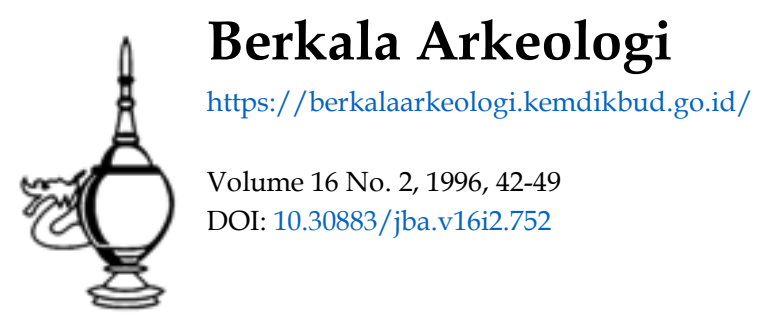

\section{cc) (7) (2)}

This work is licensed under a Creative Commons Attribution-NonCommercial-ShareAlike $\underline{4.0 \text { International License. }}$ 
BENCANA ALAM DAN KERJA BAKTI MASA JAWA KUNA. SERTA CATATAN LAIN TENTANG PRASASTI NGAÑJATAN

\author{
Rita Margaretha Setianingsih \\ (Suaka Peninggalan Sejarah dan Purbakala DIY)
}

\title{
1. Pendahuluan
}

Kerja bakti adalah hal yang masih mewarnai kehidupan kita seharihari. Di berbagai lingkungan, aktivitas itu dijalankan secara rutin, mengantisipasi peristiwa-peristiwa tertentu dan dalam beberapa kesempatan juga dilakukan untuk membantu merehabilitasi daerah yang terkena bencana alam

$\mathrm{Hal}$ tersebut sebetulnya bukan sesuatu yang baru. Sejak lama aktivitas itu telah dilakukan. Data mengenainya banyak dijumpai dalam berbagai sumber sejarah. Sebuah data baru berupa prasasti yang baru ditemukan juga mempertegas informasi tentang hal itu.

Prasasti dimaksud berupa dua buah lempengan terbuat dari bahan perunggu. Satu sisi dari masing-masing lempengan itu berisi guratan huruf yang terdiri atas 12 baris tulisan. Prasasti Ngañjatan ${ }^{1}$ yang menggunakan huruf dan bahasa Jawa Kuna ini sekarang berada di Suaka Peninggalan Sejarah dan Purbakala Daerah istimewa Yogyakarta.

1 Kedua lempengan perunggu bertulisan itu ditemukan penduduk pada tahun 1996 dalam sebuah gua di bukit Cabe yang terletak sekitar $1,5 \mathrm{~km}$ dari pemukiman Dusun Mojosari. Desa Hargosari, Kecamatan Tepus, Kabupaten Gunung Kidut, Yogyakarta. Lokasi tepatnya, berada sekitar 11 meter dari mulut gua, prasasti itu ditemukan bersama-sama dengan sebuah bokor berbahan perunggu. Ukuran masing-masing masing-masing lempengan adalah: panjang $48 \mathrm{~cm}$, lebar $18 \mathrm{~cm}$, dan tebal $0,2 \mathrm{~cm}$, sedengkan bokor berpegangan yang seluruh bagian tubuh dan dasamya berisi hiasan berbentuk bulatan itu berdiameter $11,5 \mathrm{~cm}$ dengan tinggi $15 \mathrm{~cm}$.

Karena dalam prasasti berulangkali disebutkan daerah Nganjatan, dalam penulisan kati ini name tersebut digunakan sebagai nama prasastinya. Penulis menyadari bahwa hal itu bukanlah "harga mati", artinya tetap terbuka kemungkinan bagi siapapun untuk member penamaan lain yang dianggap lebih cocok, sebatas adanya argumentasi yang tepat.

Hal lain yang perhu disampaikan, adalah rasa hormat penulis kepada Drs. Mohammad Romli, Kepala Suaka Peninggalan Sejarah dan Purbakala Daerah Istimewa Yogyakarta, atas dukungan yang diberikan hingga tulisan sederhana ini sampai ke hadapan sidang pembaca yang budiman 


\section{IsI Prasasti}

Isi dari prasasti yang berdasarkan paleografisnya berasal dari abad $X-X 1^{2}$ ini, secara garis besar menyebutkan tentang penduduk Ngañjatan yang melakukan kerja bakti (mabuñcang hajya) di daerah Girimbangi yang terlanda angin kencang dan merusak sawah. Penduduk Ngañjatan yang menyebar sampai di lembah gunung di daerah Girimbangi, semuanya bermatapencaharian dengan bertani di sawah. Oleh Sang Maharaja Kudi yang bertahta di Ngamitamanggala, mereka diingatkan akan kejadian pada waktu dulu, pada saat sawah-sawah tersebut terkena angin kencang. Sehingga para petani dan thani bala ${ }^{3}$ di Girimbang। diharapkan untuk bekerja bakti setiap hari demi kesejahteraan rakyatnya.

Anugerah yang diberikan oleh Sri Maharaja Kudi itu juga disertai dengan harapan agar Girimbangi menjadi daerah gunung yang berguna. Bukti pengesahan anugerah yang ditandai dengan prasasti itu juga disertai dengan pemberian pasek-pasek kepada Mpungku Aryya Tiyasa dan Mpungku Si Nada yang berada di Tinaker atas jasanya membuat patung dan singasana Sang Buddha.

Sebagaimana umumnya prasasti-prasasti lain, prasasti Ngañjatan ini juga memuat nama-nama mangilala drabya haji, yakni: pakalungkung. kestasangan, tpungkawung, sungsung pangurang, pasukalas, sipat, wilut, jungkung, panginangin, pamawasya, hopan, sandunglamur, panrangan, skartahun, pabayai, dan seterusnya (lihat transkripsi yang disertakan). Semuanya, sebagaimana disebut dalam prasasti, dikatakan tinggal dalam lingkungan tembok kota dan merupakan abdi raja dan golongan dalam (watak i jro).

Hasil pengelolaan drabya haji ini seluruhnya dibagi tiga (tri bagan). masing-masing diperuntukan bagi Sobharahawi, Badara, dan sebagian lagi untuk Dang Sang Wsa. Sayang sekali, ketiga nama-nama yang disebutkan itu tidak disertai dengan keterangan tentang siapa dan apa kedudukannya dalam struktur kerajaan.

Kita juga menjumpai penyebutan mengenai sukha-duhka (segala tindak pidana yang terjadi dalam lingkungan daerah perdikan yang harus dikenai sanksi denda) yang diberlakukan saat itu, seperti; walu rumambat

${ }^{2}$ Bentuk huruf yang diguratkan adalah persegi empat, ditulis dengan sangat rapi dan jelas, sehingga pembacaan dapat dilakukan tanpa mengalami banyak kesulitan. Unsur penanggalan (manggala) dari prasasti tidak dijumpai pada kedue lempengan yang ditemukan. Diperkirakan bahwa kedua lempengan itu merupakan lanjutan dari lempengan lain yang tidak ditemukan dimana unsur penanggalan tertera

${ }^{3}$ Arti katanya adatah "kekuasaan than". yakni sebuah bentuk pemerintahan desa 
ing nater ${ }^{4}$, wipati, wangkay kabunan ${ }^{6}$, rah kasawur ing hawan ${ }^{7}$, matitiba $^{-6}$, mati kaganggu, mati sinamber ing glap ${ }^{10}$, hĩdu kasirat ${ }^{11}$, dūhilaten ${ }^{12}$, sāhasa ${ }^{13}$, wākkcapala ${ }^{14}$, mamijilaken wuri ning kikir ${ }^{15}$, mamuk (mengamuk), ludan ${ }^{16}$, tutan $^{17}$, angsa pratyangsa ${ }^{19}$, danda kedenda (hukuman), mandihaladi prakara (mencela), dan mayang tan pawwah ${ }^{19}$.

\subsection{Beberapa Catatan}

Selain informasi tentang terjadinya bencana alam berupa angin kencang serta kerja bakti yang dilakukan untuk mengurangi dampak yang ditimbulkannya, isi prasasti juga mengindikasikan bahwa prasasti tersebut ditemukan bukan pada lokasi asalnya. Sebagaimana telah disebutkan, ujud prasasti Ngañjatan adalah lempengan perunggu, objek yang moveable. Hal ini memberi kemungkinan yang amat besar mengalami perpindahan jauh dari tempatnya semula, dimana ia dibuat

4 "Waluhlabu yang menjalar di halaman", yang bermakna perselisihan menge-nai batas-batas tanah/pekarangan.

${ }_{6}^{5}$ Mati karena kecelakaan

6 "Mayatmangkai (manusia) yang terkena embun". Adalah suatu delik pidana di masa lalu apabila didapat mayat di pinggir desa, pada waktu pagi. tanpa diketahui asal-usulkejadiannya dan tidak dilaporkan oleh penduduk desa Sanksinya adalah hukuman denda bagi penduduk desa. Ide yang tertuang di dalamnya adalah kewajiban penduduk desa untuk secara rutin melakukan penjagaan/pengamanan lingkungan.

Artimya "ada darah yang tertumpah di jaian", yaitu jika terjadi perkelahian yang membawa pertumpahan darah tanpa diketahui dan dilaporkan oleh penduduk desa.

Mati karena terjatuh.

Mat karena terganggu.

Mati karena tersambar petir

Meludahi orang lain.

${ }^{12}$ Menuduh orang berbuat sesuatu yang ternyata tidak dilakukannya (=mem. fitnah).

13 Tindak kekerasan.

${ }_{14}^{14}$ Memukul dengan kata-kata (memaki).

${ }^{15}$ Mengancam dengan senjata tajam.

${ }_{18}^{18}$ Mengejar musuh yang telah lari dan membunuhnya

Memperkosa.

${ }^{18}$ Bunuth-membunuh Arti kata ini sama dengan yang juga dikenal sebagai hingsa pratihingsa

${ }^{18}$ Arti harfiahnya adalah "mayang (bunga pohon pinang) yang tidak menjadi buah". yang dapat ditafsirkan sebagai ingkar janji. 
dan disampaikan kepada penduduk Ngañjatan di daerah Girimbangi sebagai bukti disyahkannya anugerah raja.

Tempat ditemukannya prasasti itu adalah gua di bagian wilayah Pegunungan Seribu. Hingga sekarang, di daerah tersebut tidak banyak dijumpai persawahan. Hal Ini berbeda dengan setting kewilayahan yang diinformasikan dalam prasasti. Prasasti Panjatan jelas menunjukkan bahwa lokasi diterimakannya prasasti itu adalah daerah yang memiliki persawahan dengan penduduk yang seluruhnya hidup dari usaha pertanian di sawah. Sehingga ketika angin kencang melanda, persawahan hancur, Sri Maharaja Kudi berkenan untuk melindungi rakyatnya dengan berusaha merehabilitasi lahan yang menjadi sumber-pangannya.

Apabila ini dapat dianggap sebagai petunjuk bahwa yang dibicarakan dalam prasasti itu tidak sama dengan tempat penemuannya, tentunya kita harus memberikan alternatif jawaban tentang wilayah yang dibicarakan. Beberapa catatan di bawah ini mungkin dapat membantu penentuannya.

Wilayah kerajaan di masa pemerintahan raja Balitung hingga Airlangga terbagi atas beberapa satuan wilayah. Salah satunya adalah wanua, yang berdasarkan data prasasti diketahui bahwa setiap wanue dipimpin oleh beberapa orang rema. Wanua dapat diartikan sebagai desa masa sekarang, dan merupakan satuan pemukiman terkecil dalam ma. syarakat Jawa Kuna. Dasar pengelompokan masyarakat di sebuah Wonue itu masih dikuasai oleh sifat-sifat kekeluargaan, dan hanya karena secara sifat kesukarelaan saja mereka tunduk pada penguasa yang paternalistik dan (diharapkan) penuh kebaikan hati.

Beberapa wanua bergabung dalam kelompok yang lebih besar yang disebut watak. Roda kehidupan watak bergantung pada puncak pimpinannya, yakni Rakai. Rakai atau rakryan memang diketahui berlaku sebagai seorang penguasa daerah, adapun watak sebagai wilayah otonom juga memiliki organisasi pemerintahan tersendiri. Istilah watak tidak lagi dikenal pada masa Kadiri, demikian pula wanue Satuan administrasi wilayah yany terkenal pada masa Kadiri ini adalah thani Thani seperti juga wanua, adalah satuan wilayah yang mempunyai wujud fisik (Sedyawati, 1994:267). Kalangan thani ini mempunyai pemerintahan sendiri, serta secara umum dikenal pada masa Singhasari, yang disebut dengan theni bala (Brandes, 1913:190).

Nama thani bele ini juga ditemukan pada prasasti Ngañjatan, yang menyebutkan, bahwa kepada para theni bala dl Girimbangi diberikan prasasti oleh Sang Maharaja Kudi Disebutkan pula yang melaksanakan kerja bakti di sana adalah para petani sawah yang menjadi penduduk Sri Maharaja Kudi, penguasa bijak yang bertahta di Ngamrtamanggala 
Kemunculan kata Ngamrtarnanggala dalam prasasti Ngañjatan membawa ingatan kita pada kisah-kisah yang diceritakan dalam Mahabharata dan Bharatayudha Diketahui bahwa cerita-cerita itu mulaı dikenal pada masa pemerintahan Raja Dharmawangsa Teguh la me mang dikenal sebagai seorang raja yang menaruh perhatian akan kesusasteraan Pada masa pemerintahannya, kitab-kitab klasik Adiparwa. Wirataparwa, Bhismaparwa, dan Utarakanda telah disadur ke dalarn bahasa Jawa Kuna Boleh jadi bahwa Jawa Timur pada saat itu jauh lebih mengenal akan nama-nama yang tertera dalam kisah-kisah pada kitabkitab klasik itu.

\section{Penutup.}

Mengakhiri tulisan singkat ini, sebagai pengantar bagi yang ingin lebih mengenal keberadaan prasasti Ngañjatan sebagai, data baru yang diharapkan berguna dan dapat dimanfaatkan untuk mengisi celah-celah yang terdapat dalam gambaran kesejarahan Nusantara pada masa klasik, mungkin tidak berlebihan bila disebutkan bahwa prasasti itu berasal dari Jawa Timur. Bahwa objek tersebut belakangan ditemukan di wilayah Daerah Istimewa Yogyakarta, hal itu sendiri merupakan bentuk lain dari perjalanan sejarahnya.

\section{Kepustakaan}

de Casparis, JG, 1975. Indonesian Paleography: A History Of Writing In Indonesia From Beginning to C. AD 1500. Leiden: EJ Brill

Sedyawati, Edi, 1994. Pengarcaan Ganesa Masa Kadiri Dan Singhasari. Sebuah Tinjauan Sejarah Kesenian. Jakarta: LIPIRUL

\section{Transkripsi Prasasti Ngañjatan}

\section{Lempeng 1}

1 mpalang pakalungkung kastasangan tpungkawung. sungsung pangurang. pasukalas. sipat wilut jungkung. pānginangin pamawasya hopan sandunglamur. panrāngan. skartahun pabayai pangtwa 
2. rāmanang. panagañlada. pakananga tampe siring pintapalaku tulunghutang. painaya. kipakipah. pawalanda patentahun paniring patarung. patarub pakikis paprāyascitta.

3. awuran. pawuwuh tandan kḍ walyan. sambal sumbul hulun haji. jenggi. panulungwulung. widu mangidung. singgah pamrsi watek i jro ityewamadi kabaih antan tama ta ya iri

4. keng wanwa ri Ngañjatan sanuktyan. sang hyang kudi ri ngamrtamanggala. samangkana $i$ tani sukhaduhkha mageng madmit kadyangga ning mayang tan pawwah walü rumambat ing natar wipati. wamgkay kabunan. rāh ka

5. sawa (wur) ring hawan. matitibā. matikaganggu. matisinamber ing glap. hî̃du kasirat. dūhilaten. sāhasa. wăkcapala. mamijilaken

6. wuri ning kikir. mamūk. mamungpang. lūdān. tutản. angsa pratyangsa. danda keḍenḍa maṇ̣ihaladi prakära. an sang hyang kudi i ngamrtamanggala asramaña irikā samangkana $;$ tani sawahadyawahara rasatamelah i sang hyang kudi ring ngam!tamanggala. an kapwa ya hïningan

7. na sri mahārāja. kramanya. matitih satulit alaway sapangiga. awasana satuhan. angawari satuhan. pakajangan satuhan pahïdhanan satahun. amananten, sapahawyan. ya

8. pwan sinikal dwal kadyāngga ning pda muan awan kamirihbawang. lada pipakan. ing larungun. kasumbha. waja krmata. hadus atak bräs. kadasa. waḥ. sepgah. pisang.

9. --dyanamadi kabeh mantagaga sabantalan jugaya wsi wsi sang sakerika yapwan sangulung - präbanya kbowanya yan pu si prānara sapyanya yan pangulang -.. 4 da

10 yan mas yan ndas praparu. wdusan. itik sawanka yanabretan rdang dananwa aparahū sasiki ikakāta kabeḥ kan knānāta ya nāsan drabya haji .... asing sadesa parăh

11 ...yanwa panday wsi. gangsa. tamrā mas sapapgâan sowang nguni warah $i$ tani sang hyang namañaru mabiswun maawring manglākha mamahang. wamungkudu manunawukudu 
12 tbari manganamanam. magawäy payung rungki, tangge, wakul kalasā. magaway kisī mankib manuk mamisandung manuk makalakal(a). mamula manawi andi - ya i ngam!

\section{Lempeng 2}

1. manggalätah bramaña i sadrbya hajinya kabaihkramanya tri- bāgan sadümān mapaknāi badāra sadūmān mapaknā $i$ dang sang wṣa pahab swa samananā ni saparikha ranikapa

2 haywan sang hyang kudi ri ngamrtamanggalā sadüman bapanniha sang karmmanya mangkana tingkah sobharahawi huwus tkap dari sang hyang räja prasasti. pagepageh i kasusukan sang hyang ku

3. di ri ngamrtamanggala. māri taparnna. nikang wanwa ri Ngañjatan thänibala girimbangi. mangkana ikanang Imaḥsawah kanginanginan tka ri kebwunya blah 1 sahumus kapäda. mantenatah parnnah nikä Ima

4. h kānginanginan an sangkai. kewala sang hyang kudi ri ngamrtamanggalähtah pramana irikä kabain tka ri salbak wukirnya kabaih̆ matani sawah prakāra kunang pwa de yakna nikang wanwa

5. ri Ngañjatan tka ring tani gamamarāsraya antapwätah kumatuturakn angsa purbwasthiti. pratidina mabuñcang hajya ring sama nanā $n$ ! kapa haywan sang hyang kudi i ngamrtamanggala angken. manis. ku

6 mendheng tita tka ri ka de yakna nikanang pinghai makukuruganakthā niwaken girimbangi tka ri sapinggir siring nikang wanwa n’ Ngañjatan karuhun sang inanugrahan srí mahäräja mapakna irikang girimba

7. ngi. tka ri sanganä thaniweh girimbangi äpan bãnibaken girimbangi tatwa bhūtanya nguni. samangkana samgat angin angin. mangtai lawan sang anagatangin angin adhumatetye nāta sira damīmbūhasa

8 kaparipürnnākna niodamel srí mahārăja sang hyang kudi i ngamrtamanggala. makawungkanna i tan hana nira deyan damuhalaha ikanang wanwa i Ngañjatan tka ri sawahnya mwang ikanang Imah sawah kä 
9. anginanginan nguniweh kebwanya blał 1 yathanya tan pamuhara prmadamageng i sira. apan samgat pagehni rasa sang hyang raja prasasti page pageh i kasusukan ikanang wanwa i Nganjatan masawah tampah 1

10. blah 1 lawan ikanang sawah Imah kanginangin tka ri kebwanya blah 1 nguniweh lbak wukirnya kabaih mangkana rasa sang hyang jnana haji prasasti page pageh ri kasusukan ikang wanwa ri Nganjatan tka ring sawahkangi-

11. nanginan de sri maharaja. bhasanget pwa mpungku i tinaker 'rrya tisaya nika wangunan sang hyang buddha säsana de srimaharaja. $r$ huwus mpungku i tinaker si nada blakan srı maharaja kudi ri ngam(r)tama

12. nggala. an de nadi ni buddha partiwimba namahkara mpu(ng)ku i tinaker. maka buktyan ikanang wanwa i Ngañjatan lawan ikanang sawah Imah kanginanginan matang yan panghaturaken mpungku i tinaker mas 5 ma

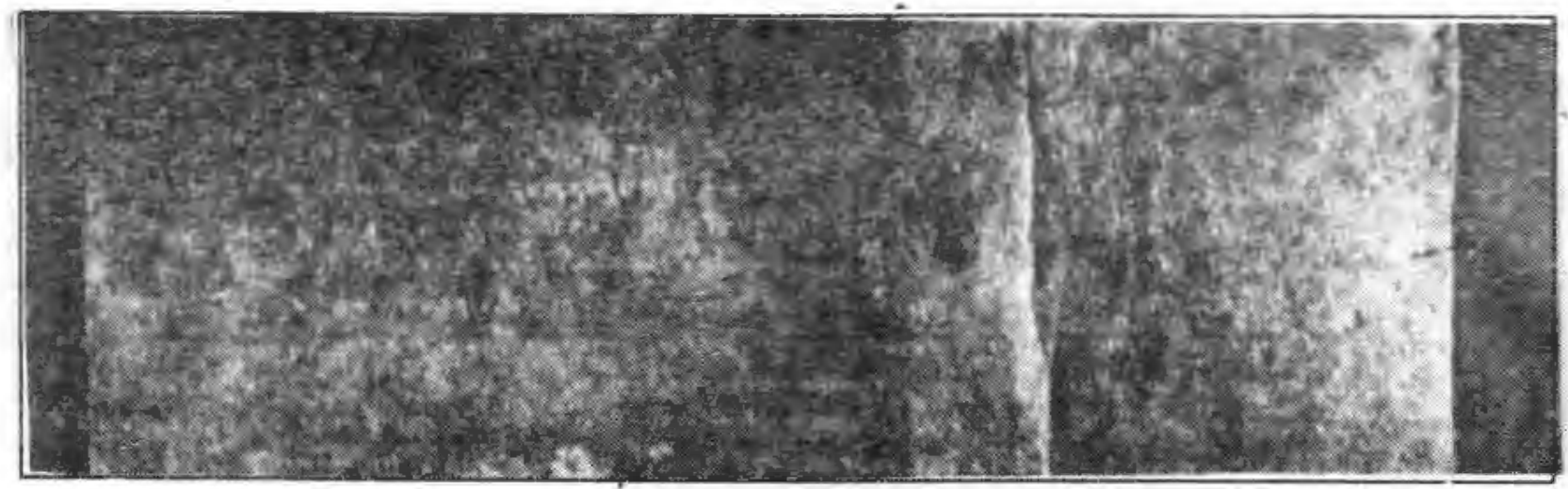

Prasasti Nganjatan lempeng 1

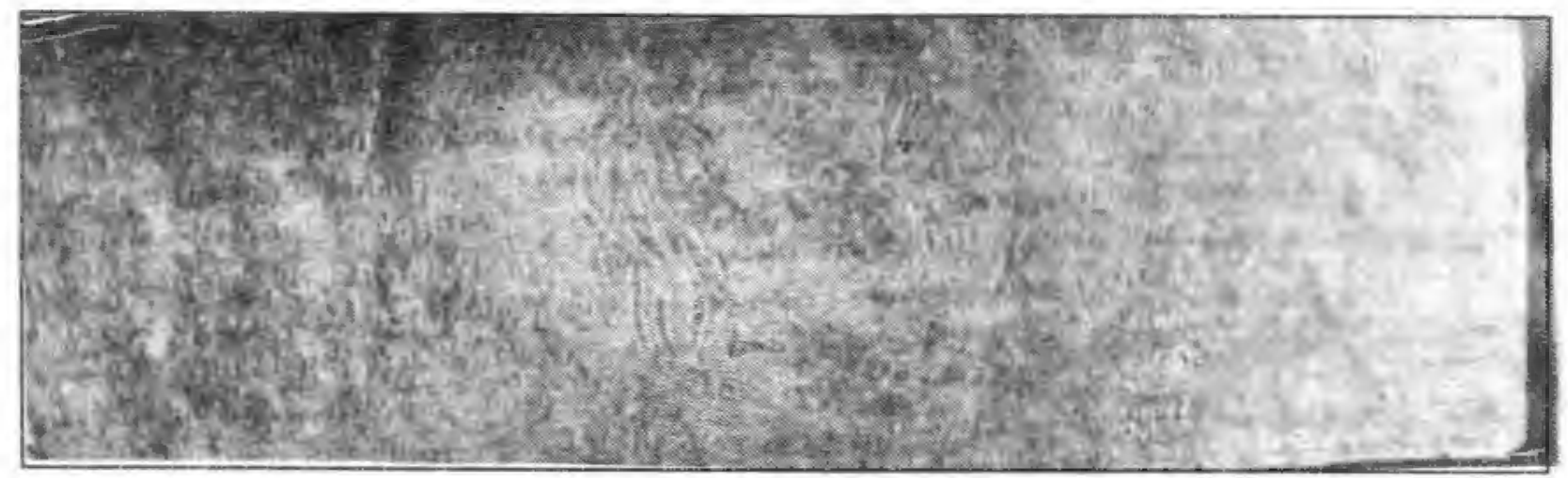

Prasasti Nganjatan lempeng 2 